\title{
INSTITUTIONAL STAPHYLOCOCCAL INFECTION AND THE MEDICAL OFFICER OF HEALTH
}

\author{
J. F. Skone, M.D., D.P.H. \\ Deputy Medical Officer of Health, City and County of Bristol \\ Formerly County Medical Officer of Health, Isle of Wight
}

BETWEEN I957 and 1959 three outbreaks of institutional staphylococcal infection were reported in the Isle of Wight. The clinical features of the outbreaks and the administrative action taken are summarized in the following notes:

\section{Outbreak I}

Enquiries made in a busy maternity unit and among district midwives, showed that among 186 births between 26th February and 14th April, 1957, 24 babies developed superficial vesicular or pustular skin lesions, but none was seriously ill. Staphylococci isolated from the skin lesions were mainly of phage types $3 \mathrm{~A}$ and $52 / \mathrm{A} / 79$.

A hospital medical officer and several of the laundry staff had positive nasal swabs. Two pupil midwives who suffered from enteritis in February were working in the area of another Local Health Authority in April and Staphylococcus aureus, phage type 80, was isolated from a nasal swab of one and phage type $3^{\mathrm{A}}$ from the nose and throat of the other.

Measures were introduced to reduce crowding by earlier discharges and improve control of infection in the unit. Domiciliary nursing staff were asked to report and take swabs of any skin lesions among babies and report breast abscesses among mothers, discharged from the unit.

\section{Outbreak 2}

In January $195^{8}$, a number of patients in the female admission and geriatric ward of an overcrowded psychiatric hospital had infected bed sores and boils. In May 1958, eight patients were found to be suffering from lesions including carbuncles, boils and labial infections due to Staphylococcus aureus, phage type 80. Measures taken to control cross-infection were partially successful but in September 1958, the ward sister developed acute phlebitis and phage type 80 septicæmia after an injection in the ward for a varicose vein. In October 1958 , ten patients and a member of the staff were suffering from septic lesions and five patients and three members of the staff were nasal carriers of phage type 80 .
Admissions to the hospital were largely suspended, the ward was temporarily closed and disinfected and patients with septic lesions were transferred to an infectious diseases hospital. A sterile syringe service was introduced and improved arrangements for laundering soiled linen and disposing of dressings were recommended. The hospital Control of Cross-Infection Officer and the county and district medical officers of health recommended that the numbers of patients in the hospital should be reduced from 454 to 380 ; 45 female patients were transferred to another hospital. The county medical officer and secretary of the Hospital Management Committee notified general practitioners of the outbreak and the administrative action necessary and asked them to take swabs from any septic focus occurring in a non-resident member of the hospital staff under their care.

\section{Outbreak 3}

An outbreak due to Staphylococcus aureus, characterized by persistent, low-grade infections of the skin, occurred in a residential school for delicate children. The first cases occurred in October 1958. Three boys, all in the same dormitory, developed boils. One had been admitted about six weeks previously and the other two, one of whom had had recurrent boils since admission, about 12 months before. Because of the outbreak in the psychiatric hospital, nasal swabs and swabs from the lesions were taken from these three boys. From each swab Staphylococcus aureus, phage type 8o, was isolated. Nasal swabs were taken of all the remaining children and members of the school staff. There were 150 children in the school and 62 staff; swabbing had to be spread over several weeks because the laboratory was heavily committed on account of similar infections elsewhere.

In the course of the investigation 12 symptomless nasal carriers came to light. Three of them subsequently developed skin lesions and there were a further nine children with styes or boils from which Staphylococcus aureus, phage type 80, 
was recovered. In addition, earlier in the outbreak, a boy was admitted to hospital with an acute suppurative parotitis which yielded the same organism. One of the nursing staff developed a whitlow and a clerical assistant had pneumonia: in each case Staphylococcus aureus, phage type 8o, was found.

Carriers and cases were isolated and nasal carriers were treated by means of an ointment containing neomycin and gramicidin applied locally, further swabs being taken at six-day intervals. Treatment was continued until two negative swabs had been received, and on average each child had a minimum of nearly three weeks' treatment, most of the children being clear at the end of this time. Admissions to the school were suspended and principal school medical officers of other authorities sponsoring pupils were informed of the outbreak.

By the end of January 1959, the infection appeared to have been eradicated, but it lit up again and a few more cases of skin infection occurred, before it was finally brought to an end in April of that year.

\section{Discussion}

Ministry of Health Circulars in 1950 (H.M.C. (50)2 I) and in 1953 (H.M.C.(53)36) emphasized the importance of keeping the Medical Officer of Health fully informed of outbreaks of communicable disease in hospital. The circular on the Control of Staphylococcal Infections in Hospitals (H.M.(59)6) drew attention to the importance of adequate liaison with bodies other than the Hospital Management Authority, e.g. Regional Hospital Boards, Medical Officers of Health and Executive Councils.

The control of staphylococcal disease is not merely the province of a particular department of a hospital but one which involves the hospital as a whole and the community in which it is situated. General practitioners and medical officers of health can assist hospital authorities by informing their hospital colleagues of infections among patients, both before admission and after discharge. Outbreaks of hospital sepsis may result in the closure of wards and redeployment of Local Health Authority staff.

In an outbreak in a residential school it is difficult to separate the infected from the uninfected children. Sick bay accommodation is generally limited and it is difficult to segregate children when dining rooms, recreational rooms and toilet facilities are adequate only in ordinary circumstances. Fortunately in Outbreak 3, a number of the dormitories were contained in separate houses scattered about the school grounds, and it was possible to group all the symptomless carriers in two dormitories in one building; the children with lesions being isolated in the sick bay or the local infectious diseases hospital.

The Public Health Committee of the B.M.A. has recommended that neonatal infection (any coccal disease of a child within 2 I days of birth) should be notifiable.

\section{Summary}

An account is given of three outbreaks of staphylococcal infection that occurred in a Local Health Authority in 1957 and 1958 . The administrative action taken is summarized and the importance of close co-operation between hospital and community health service is emphasized.

I wish to acknowledge the assistance given in the preparation of this paper by Dr. K. F. Alford; Dr. E. F. Burndred; Mr. F. L. W. Eade; Dr. G. Gordon Brown; Dr. K. E. Hughes; Dr. R. K. Machell; Dr. John Mills; and Dr. P. D. Swinstead.

\section{REFERENCES}

Staphylococcal Infections in Hospitals (1959): Report of Sub-Committee of Central Health Services Council, p. 29. The Health of the School. Child (1958 and 1959): Report of the Chief Medical Officer of the Ministry of Education, p. 147.

Notification of Infectious Diseases (1959): Report of the Infectious Diseases Sub-Committee of the Public Health Committee, Brit. med. $\mathcal{F}$., i, 172 (Suppl.). 